\title{
The Impact of Government Policy on Food Pricing Using Game Theory
}

\author{
Negin Deljouyan Davood Jafari ${ }^{*} \quad$ Asghar Darigh \\ Department of Industrial Engineering,College of Engineering,Parand Islamic Azad \\ University,Parand,Tehran,Iran
}

\begin{abstract}
In this research, a model based on the theory of competitive games using Nash equilibrium and in the presence of a retailer for the purpose of food pricing was presented in terms of state competition and policy. Considering the effects of government competition and policy on the issue, we are trying to make a model more in line with real-world conditions and used by managers and practitioners in the food industry. Ultimately, the sensitivity analysis plant production costs were taken and the effect of changes in parameters on the variables of the research was measured.
\end{abstract}

Keywords: pricing, food products, competition, government policy, game theory.

DOI: $10.7176 /$ IEL/9-4-06

Publication date:May $31^{\text {st }} 2019$

\section{Introduction}

Today, with the industrial and economic development, the number of manufacturers in each industry has increased sharply and customers can choose from a variety of brands. In fact, the right to choose customers has increased dramatically, and they do not have to be limited to a specific brand. According to these, manufacturers have no choice but to arm new tools in order to attract customers. In particular, companies and organizations of the nature of production must sell their products in any way, and this can be achieved by purchasing customers so that organizations seek to satisfy their customers and strive to maintain their market and survival. In this regard, there have been some solutions, one of which is supply chain management. Over the past decades, supply chain management has been highly regarded by researchers.

Trade globalization, increased competition, and closer alignment of products in terms of quality are among the issues that have pushed industries and research institutes into further studies on more efficient and effective management of operations. Hence, studies in the supply chain have been developed and researchers and officials have always tried to use the supply chain management techniques to match business processes and activities between the relevant levels in order to improve the overall performance and efficiency of the supply chain. (Pahlavani, 2014).

In the past, most of the decisions regarding the supply chain of companies, such as inventory control, pricing, supplier relations, and similar issues, were based on the experience of corporate management or the expertise of the companies concerned. But today the complexity of the business environment, as well as the decisions to be made, necessitate the adoption of precise scientific approaches to help management to make critical decisions in the supply chain (Chapman and Razi Bazaki, 2016). One of these very important decisions is the pricing of products that has a significant impact on the success of manufacturing and service companies (Ki and Bai, 2017). For this purpose, it is necessary to use the tools and techniques available to provide tools to help managers of manufacturing companies to determine the optimal price of manufactured items.

\section{Research methodology}

There are several ways to conduct research in which choosing a research method depends directly on the purpose, subject, and facilities. In other words, the purpose of choosing a research method is to determine whether the researcher wants to use which approach to achieve the goals and answer research questions. Choosing an appropriate research method can help researchers to access research goals faster and more accurately, and possibly at a lower cost, so that choosing the appropriate research method is very important.

One of the most important factors that can guide the researcher is to make him more accurate, easier, faster and less costly to pursue his research and obtain more reliable results from his findings. Choosing the appropriate research method is reasonable.

\section{Categorization of research based on the purpose}

Scientific research is divided into three categories according to the purpose:

Research and Development

Fundamental research

Applied research. 


\section{Categorization of research based on the way of data collection}

1. Experimental research

2. Descriptive research (non-experimental)

- Survey research

- Correlation research

- Action research

- Case Study

- Ex-post factor research

The present study is descriptive in terms of its methodology, since it examines the current state of a system. In terms of purpose, this research is an applied research because, in addition to theoretical aspects, it is capable of enjoying real-world affairs, and this provides a practical aspect to the research. The application of this research is specifically aimed at helping managers and decision makers in the field of production and distribution of food products that can exploit the results of this research as a useful and effective tool in their decision making and planning.

\section{3-3- Methods for data collection}

In this research, the following methods are used to collect data:

\section{A. Library Studies}

The study of library resources has always been a major source of data. In this research, library studies have been used extensively in order to collect the data on literature and research background.

The library resources used in this research include:

- Books

- $\quad$ articles

- theses

- Available documents

- Projects taken

- Internet information resources

\section{3-4- Research steps}

The present research steps can be summarized as follows:

\section{3-4-1- Review the literature of research}

In the first step, a review of the literature is underway. So in this step, by studying library resources such as books and articles, proper knowledge of the subject matter and the theoretical foundations as well as studies done in the literature of the topic under consideration and the exact evaluation are presented. In this step, we try to study the analysis of the gaps in the subject literature, to get a deep understanding of the issue under study, as well as the research gaps in the subject literature, and thus the activities and research that is being carried out in this context. Research has to be made to identify these gaps.

\section{3-4-2- Designing the Research Model}

After reviewing the literature in the previous step, at this stage, the design of the research model is being carried out. In this step, the design of the parameters, variables, and constraints is done in order to know the exact problem, and the research model is presented.

\section{3-4-3- Numerical Tests}

In this step, designing issues in a variety of ways is done to do numerical tests. In this step, issues are designed in a variety of ways and using the approach presented, the problems are solved and the results are presented in the form of numbers and figures and tables.

\section{Results}

Numerical issues

In this section, we present two numerical examples in the monopolistic market environment and the competitive market to compare the best scenarios. In all of these, there are two scenarios, two producers and two retailers. The data generated by inspiration from some of the papers published in the literature of the subject, such as Chab and RastiBarzaki (2016), are designed in accordance with the parameters presented in this research.

\section{4-2-1- Problem 1}

Information about model parameters can be seen in Table 1. 
Table 1. Problem Information Issue 1

\begin{tabular}{cccccc}
\hline$\bullet$ Second scenario & $\bullet$ First scenario & $\bullet$ Parameters \\
$\bullet$ & $\mathbf{8 0}$ & $\bullet$ & 80 & $\bullet$ & 80 \\
$\bullet$ & $\mathbf{5 0}$ & $\bullet$ & 50 & $\bullet$ & 50 \\
$\bullet$ & $\mathbf{9 0}$ & $\bullet$ & 90 & $\bullet$ \\
\hline$\bullet$ & $\mathbf{0 . 2}$ & $\bullet$ & 0.2 & $\bullet$ & 0.2 \\
\hline$\bullet$ & $\mathbf{0 . 3}$ & $\bullet$ & 0.3 & $\bullet$ & 0.3 \\
\hline$\bullet$ & $\mathbf{0 . 7}$ & $\bullet$ & 0.7 & $\bullet$ & 0.7 \\
\hline$\bullet$ & $\mathbf{5}$ & $\bullet$ & 5 & $\bullet$ \\
\hline$\bullet$ & $\mathbf{4}$ & $\bullet$ & 4 & $\bullet$ \\
\hline$\bullet$ & $\mathbf{0 . 1}$ & $\bullet$ & - & $\bullet$ & 0.1 \\
\hline$\bullet$ & $\mathbf{0 . 3}$ & $\bullet$ & - & $\bullet$ & 0.3 \\
\hline$\bullet$ & $\mathbf{1 0}$ & $\bullet$ & - & $\bullet$ & 10 \\
\hline$\bullet$ & $\mathbf{2 0}$ & $\bullet$ & - & $\bullet$ & 20 \\
\hline
\end{tabular}

By solving the problem, the results are described in Table 2.

Table 2. Problem Solving Issues Issue 1

\begin{tabular}{|c|c|c|}
\hline - Second scenario & - First scenario & Parameters \\
\hline$\bullet 136.0518$ & $\bullet 135.8333$ & - $p_{11}$ \\
\hline • 103.0077 & • 102.3889 & • $p_{11}$ \\
\hline - 130.4220 & - 129.8889 & - $p_{22}$ \\
\hline - 136.0518 & - 135.8333 & $w_{1}$ \\
\hline$\bullet 80.1586$ & • 79.7778 & - $w_{2}$ \\
\hline - 5361.2013 & $\cdot 5339.7133$ & $\pi_{R 1}$ \\
\hline • 1263.2061 & $\cdot 1255.5617$ & $\pi_{R 2}$ \\
\hline - 5143.7813 & • 5135.2083 & • $\quad \mu_{f 1}$ \\
\hline - 2597.0073 & - 2584.0222 & - $\quad \mu_{f 2}$ \\
\hline
\end{tabular}

\begin{tabular}{|c|c|c|}
\hline - Second scenario & - First scenario & - Parameters \\
\hline$\bullet 40$ & $\cdot 40$ & $\bullet$ a11 \\
\hline$\cdot \mathbf{5 0}$ & $\cdot 50$ & - a21 \\
\hline$\cdot 40$ & $\cdot 40$ & - a22 \\
\hline$\bullet 0.3$ & $\bullet 0.3$ & - b11 \\
\hline$\bullet 0.4$ & $\cdot 0.4$ & - b21 \\
\hline$\bullet 0.5$ & $\bullet 0.5$ & - b22 \\
\hline$\bullet 6$ & $\cdot 6$ & $\bullet \mathrm{c} 1$ \\
\hline$\cdot 6$ & $\cdot 6$ & $\cdot \mathrm{c} 2$ \\
\hline$\bullet 0.2$ & $\cdot$ & . $\quad \alpha_{1}$ \\
\hline$\bullet 0.2$ & - $\quad-$ & $\alpha_{2}$ \\
\hline$\cdot 15$ & - $\quad-$ & . $I_{1}$ \\
\hline$\cdot 15$ & - $\quad-$ & - $I_{1}$ \\
\hline
\end{tabular}

As can be seen from the variables table, according to the example produced, the profit of the retailer and the producer in the second scenario is greater than the first scenario. On the other hand, the producer's profit in a multiple competition mode is less than that of monopolistic competition in both scenarios. Be

4.2.2 Problem 2

Producer and retailer information is shown in Table 3. 
Table 4-3 Problem Information problem 2

By solving the problem, the results are described in Table 4.

Table 3. Problem Solving Problems Issue 2

\begin{tabular}{|c|c|c|}
\hline - Second scenario & - First scenario & - Parameters \\
\hline$\bullet 69.95$ & $\bullet 69.67$ & . $p_{11}$ \\
\hline$\bullet 73.94$ & $\cdot 73.73$ & - $\quad p_{21}$ \\
\hline$\cdot 63.89$ & $\cdot 63.73$ & - $p_{22}$ \\
\hline$\bullet 69.95$ & • 69.67 & $w_{1}$ \\
\hline$\bullet 47.56$ & - 47.44 & - $w_{2}$ \\
\hline - 1504.743 & - 1492.24 & $\pi_{R 1}$ \\
\hline$\cdot 133.29$ & $\cdot 132.48$ & $\pi_{R 2}$ \\
\hline • 1221.47 & • 1216.03 & . $\quad \mu_{f 1}$ \\
\hline • 775.236 & • 772.94 & . $\quad \mu_{f 2}$ \\
\hline
\end{tabular}

As it can be seen from the variables table, in this case, the retailer's and producer's profits in the second scenario are more than the first scenario. On the other hand, the producer's profit in multiple competition situations is less than that of monopolistic competition in both scenarios.

\subsubsection{Problem \#3}

Producer and retailer information is shown in Table 4.

Table 4. Information of Problem Number 3

\begin{tabular}{ccccccc}
\hline Parameters & $\bullet$ & First scenario & $\bullet$ & Second scenario & $\bullet$ \\
\hline $\mathrm{a}_{11}$ & $\bullet$ & 100 & $\bullet$ & $\mathbf{1 0 0}$ & $\bullet$ \\
\hline $\mathrm{a}_{21}$ & $\bullet$ & 100 & $\bullet$ & $\mathbf{1 0 0}$ & $\bullet$ \\
\hline $\mathrm{a}_{22}$ & $\bullet$ & 65 & $\bullet$ & $\mathbf{6 5}$ & $\bullet$ \\
\hline $\mathrm{b}_{11}$ & $\bullet$ & 0.5 & $\bullet$ & $\mathbf{0 . 5}$ & $\bullet$ \\
\hline $\mathrm{b}_{21}$ & $\bullet$ & 0.35 & $\bullet$ & $\mathbf{0 . 3 5}$ & $\bullet$ \\
\hline $\mathrm{b}_{22}$ & $\bullet$ & 0.25 & $\bullet$ & $\mathbf{0 . 2 5}$ & $\bullet$ \\
\hline $\mathrm{c}_{1}$ & $\bullet$ & 7 & $\bullet$ & $\mathbf{7}$ & $\bullet$ \\
\hline $\mathrm{c}_{2}$ & $\bullet$ & 9 & $\bullet$ & $\mathbf{9}$ & $\bullet$ \\
\hline$\alpha_{1}$ & $\bullet$ & - & $\bullet$ & $\mathbf{0 . 1 5}$ & $\bullet$ \\
\hline$\alpha_{2}$ & $\bullet$ & - & $\bullet$ & $\mathbf{0 . 1 5}$ & $\bullet$ \\
\hline$I_{1}$ & $\bullet$ & - & $\bullet$ & $\mathbf{1 2}$ & $\bullet$ \\
\hline$I_{2}$ & $\bullet$ & - & $\bullet$ & $\mathbf{1 4}$ & $\bullet$
\end{tabular}

By solving the abovementioned problem, the results are described in Table 4-6.

Table 4-6 Results of Problem Number 3

\begin{tabular}{cccccc}
\hline Parameters & $\bullet$ & First scenario & $\bullet$ & Second scenario & $\bullet$ \\
\hline$p_{11}$ & $\bullet$ & 103.5 & $\bullet$ & $\mathbf{1 0 3 . 6 8}$ & $\bullet$ \\
\hline$p_{21}$ & $\bullet$ & 213.86 & $\bullet$ & $\mathbf{2 1 4 . 3 4} \bullet$ \\
\hline$p_{22}$ & $\bullet$ & 201 & $\bullet$ & $\mathbf{2 0 1 . 6 1}$ & $\bullet$ \\
\hline$w_{1}$ & $\bullet$ & 103.5 & $\bullet$ & $\mathbf{1 0 3 . 6 8} \bullet$ \\
\hline$w_{2} \cdot \bullet$ & 142 & $\bullet$ & $\mathbf{1 4 2 . 3 6}$ & $\bullet$ \\
\hline$\pi_{R 1}$ & $\bullet$ & 6463.33 & $\bullet$ & $\mathbf{6 4 8 7 . 2 6}$ & $\bullet$ \\
\hline$\pi_{R 2}$ & $\bullet$ & 870.25 & $\bullet$ & $\mathbf{8 7 7 . 6 4}$ & $\bullet$ \\
\hline$\mu_{f 1}$ & $\bullet$ & 4656.12 & $\bullet$ & $\mathbf{4 6 6 4 . 8 7} \bullet$ \\
\hline$\mu_{f 2}$ & $\bullet$ & 5306.7 & $\bullet$ & $\mathbf{5 3 2 0 . 9 6} \bullet$
\end{tabular}


As it is indicated in the variables table, in this case, the retailer and producer's profits in the second scenario are more than the first scenario. On the other hand, the producer's profit in multiple competition situations is less than that of monopolistic competition in both scenarios. Therefore, contrary to the hypothesis, the second scenario based on the requirement to comply with green policies not only did not reduce the profit of the components of the chain, but also it was able to increase it to some extent.

\section{Game analysis}

As discussed earlier, due to the competition between the different levels of the chain studied, the approach used in this study is to determine the appropriate product price for game theory. Considering the two main strategies, including the green service scenario (government policy) and the scenario without providing green services, the game equilibrium equations were first proposed for calculating the price, profit of retailers as well as producers, which solved these equations, optimized producer prices, and retailers, as well as their optimal profitability, were identified in a variety of strategies.

Then the exact solution model was found and the optimal values of the variables were identified for different strategies. Therefore, the model is structurally correct and has no problem in terms of modeling basics.

Also, numerical problems are solved, which are logical and acceptable results. On the other hand, sensitivity analysis was carried out and the results are logical and consistent with intuition and reality. Regarding the set of these cases, the model's veracity is verified by structural aspect and results.

The game specs used in this research are as follows:

- The game is dynamic.

- The game is considered as a complete game.

- Two main levels in the game are intended to include manufacturer and retailer.

- Each level of the game has two parts: two manufacturers and two retailers.

- The game is in a completely competitive and non-exclusive manner in any of the chain segments.

- Each of the actors seeks to maximize their desired profits.

- Competition is in the horizontal and cross-sectoral segments.

- The game has a non-cooperative mode, that is, there is no kind of partnership between the actors either vertically or horizontally.

- The game is a leader and follower, so that retailer decisions are made first and then the manufacturer decides.

- The game was designed in two main scenarios, including a green production scenario (based on government policies) and without a green production scenario (government intervention) and analyzed for each.

\section{Conclusion}

After comparative acquaintance with the concepts discussed, a comprehensive literature review of the subject literature and related research was presented. Pricing models in the supply chain were thoroughly examined to provide a basis for and guidance for research. For this purpose, by carefully examining the research and identifying the strengths and weaknesses of the research, we tried to use the positive aspects of the research and take steps to fill the research gaps. After reviewing the comprehensive literature on the subject literature, the final model was presented. In this study, two producers and two retailers were considered, one of these producers having a monopolistic market and the other having a multi-competitive market, and a producer who has a monopolistic market only sends to his retailer and a manufacturer with multiple competitive favors will give both retailers a boost. In addition, the two scenarios are defined as the first scenario without green service and the second scenario with green service. The first manufacturer only has the first and second-largest retailers, both the first and second-party retailers.

\section{Sources}

Khanlarzadeh, Narges (2013). Determining the price and policy of controlling the inventory of corrupt items with regard to the rate Time-dependent Corruption, 10th International Conference on Industrial Engineering, Tehran, Amir Kabir University of Technology.

Saif Barqi, Mehdi and Amiri, Maghsood, Heydari, Mostafa (2008). Estimation of the cost function of a two-tier inventory system in lost sales mode using regression. Industrial Engineering Magazine, 1, 1-10.

AKCAY, Y., NATARAJAN, H. P. \& XU, S. H. (2010). Joint dynamic pricing of multiple perishable products under consumer choice. Management Science, 56, 1345-1361.

Alaei S., Alaei R., Salimi P., (2014), A game theoretical study of cooperative advertising in a singlemanufacturer-two-retailers supply chain. The International Journal of Advanced Manufacturing Technology, 74(1-4), 101-111.

Axsäter, S. (2000). "Exact analysis of continuous review (R, Q) policies in two-echelon inventory systems with compound Poisson demand." Operations research 48(5): 686-696.

Axsäter, Sven. Inventory control. Vol. 225. Springer, (2015). 
Bard, J. F. and N. Nananukul (2009). "The integrated production-inventory-distribution-routing problem." Journal of Scheduling 12(3): 257-280.

Barough, A. S., Shoubi, M. V., \& Skardi, M. J. E. (2012). Application of game theory approach in solving the construction project conflicts. Procedia-Social and Behavioral Sciences, 58, 1586-1593.

Barron, C. and Sana, S.Sh. (2015). Multi-item EOQ inventory model in a two-layer supply chain while demand varies with a promotional effort. Appl. Math. Modelling.

Chaab Jafar, Rasti-Barzoki Morteza, (2016), Cooperative advertising and pricing in a manufacturer-retailer supply chain with a general demand function; A game-theoretic approach. Computers \& Industrial Engineering, 99, 112-123.

Boyaci T, Gallego G (2002) Coordinating pricing and inventory

replenishment policies for one wholesaler and one or more geographically dispersed retailers. Int $\mathrm{J}$ Prod Econ 77(2):95-111

Cachon, G. P. (2001). "Exact evaluation of batch-ordering inventory policies in two-echelon supply chains with periodic review." Operations research 49(1): 79-98.

Chan LM, Shen ZM, Simchi-Levi D, Swann JL. (2004) Coordination of pricing and inventory decisions: A survey and classification. Handbook of Quantitative Supply Chain Analysis: Springer; p. 335-92. 